\title{
Peripheral Myelin Protein 22 and Protein Zero: a Novel Association in Peripheral Nervous System Myelin
}

\author{
Donatella D'Urso, Peter Ehrhardt, and Hans Werner Müller \\ Molecular Neurobiology Laboratory, Department of Neurology, Heinrich-Heine-University, 40225 Düsseldorf, Germany
}

Mutations found in the two major glycosylated transmembrane proteins of the PNS myelin, the peripheral myelin protein zero (P0) and peripheral myelin protein 22 (PMP22), have been independently associated with the most common hereditary demyelinating peripheral neuropathies. Genotype-phenotype correlations in humans and transgenic animals have provided functional evidence that P0 and PMP22 are involved in formation and maintenance of compact myelin. Here, we demonstrate for the first time that P0 and PMP22 proteins form complexes in the myelin membrane, as shown by coimmunoprecipitation experiments, and that glycosylation is not involved in mediating these interactions. Complex formation was also detected when the two proteins were coexpressed in heterol-

Myelin is a highly specialized plasma membrane that wraps segments of axons, acting as an insulator and allowing the propagation of the electric impulses along nerves in a saltatory manner. When disrupted by disease or lesions and when the sheath fails to form normally because of defects in the genetic program, serious neurological symptoms result, including motor and sensory deficits. During development of the PNS, Schwann cells stop dividing and start to wrap axons in a loose spiral. While myelination proceeds, more turns are formed and compaction takes place, resulting in the typical multilamellar structure. Compaction is a critical feature for the correct function of myelin. This membrane consists mostly of lipids and contains a specific set of proteins. The interactions of the myelin proteins with respect to each other and to the phospholipid bilayer are not yet fully understood, but the precise arrangement of the major peripheral and integral membrane proteins must have functional implications. Changes in the amount or in the conformation of one of those components could perturb the entire structure, leading to demyelination.

Recent molecular and genetic studies have provided some insights into the structure and function of one of the integral membrane proteins of peripheral myelin, the peripheral myelin protein 22 (PMP22). The pattern of expression of PMP22 is synchronous with myelin formation, and it localizes almost exclusively in the compact sheath (Snipes et al., 1992a; Kuhn et al.,

Received Nov. 6, 1998; revised Jan. 29, 1999; accepted Feb. 10, 1999.

This work was supported by Deutsche Forschungsgemeinschaft Grant Mu 630/ 5-3. We thank Dr. H. E. Meyer (Institut for Physiological Chemistry, University of Bochum, Bochum, Germany) and his laboratory for performing protein analyses by MALDI-MS and for discussion, R. Greiner-Petter for technical assistance, and Dr. R. Martini for providing the mouse monoclonal anti-P0 antibody. We are particularly grateful to Dr. W. Stoffel for invaluable discussion of this work.

Correspondence should be addressed to Dr. Donatella D’Urso, Department of Neurology, Molecular Neurobiology Laboratory, Heinrich-Heine-University, Moorenstrasse 5, 40225 Düsseldorf, Germany.

Copyright (ㄷ) 1999 Society for Neuroscience $\quad 0270-6474 / 99 / 193396-08 \$ 05.00 / 0$ ogous cells. In transfected cells, P0 and PMP22 are recruited and colocalize at the apposed plasma membranes of expressors as shown by confocal microscopy. These findings provide a new basis for a better understanding of myelin assembly and of the pathomechanisms involved in demyelinating peripheral neuropathies. Furthermore, these results propose a possible explanation why alterations in either of these molecules are sufficient to destabilize the myelin structure and cause a similar disease phenotype.

Key words: peripheral myelin protein 22; protein zero; protein complexes; immunoprecipitation; transfection; demyelinating peripheral neuropathies

1993). Sequence analyses and topology studies have shown that the PMP22 molecule consists of four transmembrane and two extracellular domains and carries an L2/HNK1 carbohydrate chain (Spreyer et al., 1991; Welcher et al., 1991; D'Urso and Müller, 1997). Several different mutations found in the PMP22 gene have been associated with a set of hereditary demyelinating peripheral neuropathies, a heterogeneous group of genetic disorders, which includes Charcot-Marie-Tooth disease (CMT), hereditary neuropathy with liability to pressure palsies (HNPP), and Dejerine-Sottas syndrome (DSS) (for review, see Suter and Snipes, 1995; De Jonghe et al., 1997). Genotype-phenotype correlations have shown that different mutations cause phenotypes with varying degrees of disease severity, with all presenting affected myelin as a common feature, indicating that, most likely, these mutations lead to a nonfunctional protein or interfere with possible protein-protein interactions. Furthermore, duplication or deletion of the PMP22 gene is associated with the CMT1A disease phenotype, suggesting that a gene dosage effect is as well involved in the pathological mechanisms. Recently, we have studied two PMP22 point mutations, L16P and G150D, carried by the spontaneous mouse mutants Trembler J (Suter et al., 1992a) and Trembler (Suter et al., 1992b) and found in patients affected by CMT1A and DSS, respectively (Valentijn et al., 1992; Ionasescu et al., 1997). For both mutants, we showed that the protein is not transported to the plasma membrane but accumulates in the endoplasmic reticulum and Golgi compartments (D'Urso et al., 1998). When the mutant and the wild-type PMP22 coexist, only the nonmutated protein is inserted into the myelin membrane, resulting in a net decrease in the amount of functional protein. However, mechanistically it remains unclear how this could interfere with myelin stability and cause demyelination. One possible hypothesis is that different proteins form complexes within the lipid bilayer and/or between the myelin membranes. If the components of these complexes are altered because of mutations 
or because one of them is not present in the right amount, compact myelin might not be formed or might be gradually destroyed. In this context, we searched for PMP22 binding partners in peripheral myelin. In this report, for the first time we present evidence that PMP22 forms complexes with another myelin protein at the plasma membrane. Immunoprecipitation experiments, followed by mass spectrometry and Western blotting analysis, identified this protein as the peripheral myelin protein zero (P0). Enzymatic digestion to remove $N$-linked sugar chains carried by both proteins did not affect these interactions, indicating that glycosylation does not play a crucial role. Furthermore, when we challenged these results in an in vitro system, we were able to show that PMP22 and P0 complexes coimmunoprecipitated also when these two proteins were coexpressed in HeLa cells, a non-neural cell line. In cotransfected cells, both proteins were targeted to the plasma membrane in which they are highly concentrated and colocalized at the cell-cell contact sites, as clearly shown by double immunofluorescence and confocal microscopy analyses. Together, these data provide evidence for PMP22-P0 interactions at the plasma membrane. To our knowledge, this is the first demonstration of interactions between two distinct myelin proteins. $\mathrm{P} 0$ is a transmembrane glycoprotein specifically expressed by Schwann cells and localized in compact myelin. In addition, $\mathrm{P} 0$ is an adhesion molecule that belongs to the IgG gene superfamily, and several lines of evidence have shown that it is responsible for holding the myelin membrane compact via interactions of both its extracellular and cytoplasmic domains (D’Urso et al., 1990; Giese et al., 1992; Wong and Filbin, 1994). Interestingly, several P0 point mutations have been found in patients affected by CMT1B, DSS, HNPP, or congenital hypomyelination $(\mathrm{CH})$ (Warner et al., 1996; for review, see Patel and Lupski, 1994; De Jonghe et al., 1997). The data presented in this report may explain why alterations in either of the PMP22 or $\mathrm{P} 0$ proteins, possibly interfering with the formation of complexes, are sufficient to destabilize the myelin structure leading to the same pathological symptoms.

\section{MATERIALS AND METHODS}

Isolation of PNS myelin. Sciatic nerves were removed from adult rats, frozen in liquid nitrogen, pulverized, and homogenized in $0.9 \mathrm{M}$ sucrose, $10 \mathrm{~mm}$ HEPES, and $1 \mu \mathrm{g} / \mathrm{ml}$ aprotinin at $4^{\circ} \mathrm{C}$. Homogenate was overlaid with $0.25 \mathrm{M}$ sucrose and centrifuged at $100,000 \times g$ for $3 \mathrm{hr}$ at $4^{\circ} \mathrm{C}$. Myelin was collected from the interface between the two sucrose layers, homogenized in $9 \mathrm{vol}$ of ice-cold water, and centrifuged at $15,000 \times \mathrm{g}$ for $30 \mathrm{~min}$ at $4^{\circ} \mathrm{C}$. The myelin pellet was subjected to two additional cycles of osmotic shock, homogenized in $0.9 \mathrm{M}$ sucrose, $10 \mathrm{~mm}$ HEPES, and 1 $\mu \mathrm{g} / \mathrm{ml}$ aprotinin, separated again on a sucrose gradient, and rinsed twice in cold water as described above. The final pellet was resuspended in an appropriate volume of water containing $2 \mathrm{~mm}$ Pefabloc, $1 \mu \mathrm{g} / \mathrm{ml}$ pepstatin, and $1 \mu \mathrm{g} / \mathrm{ml}$ leupeptin, and stored at $-20^{\circ} \mathrm{C}$. Total protein concentration was determined with a Bio-Rad (Munich, Germany) assay kit.

Immunoprecipitations and Western blotting. Isolated myelin (or partially delipidated myelin) was diluted in buffer containing $150 \mathrm{~mm}$ sodium chloride, $1.2 \%$ NP-40, $1.2 \%$ Triton X-100, $0.1 \%$ SDS, 50 mM Tris, pH 7.5 , and protease inhibitors [ $2 \mathrm{~mm}$ Pefabloc, $1 \mu \mathrm{g} / \mathrm{ml}$ pepstatin, $1 \mu \mathrm{g} / \mathrm{ml}$ leupeptin (all from Boehringer Mannheim, Mannheim, Germany)]. To perform immunoprecipitation reactions, $100 \mu \mathrm{l}$ aliquots containing $5 \mu \mathrm{g}$ of total protein were incubated with the appropriate antibody overnight at $4^{\circ} \mathrm{C}$ with constant gentle rotation in silanized tubes. Then, $50 \mu \mathrm{l}$ of protein A Sepharose $(150 \mathrm{mg} / \mathrm{ml}$; Pharmacia, Uppsala, Sweden) was added to the samples, and the mixture was incubated for an additional 2 $\mathrm{hr}$ at $4^{\circ} \mathrm{C}$. Beads were pelleted at $1500 \mathrm{rpm}$ for $10 \mathrm{~min}$ and washed once with the immunoprecipitation buffer (containing $0.5 \mathrm{M} \mathrm{NaCl}$ ), once with $150 \mathrm{~mm} \mathrm{NaCl}$ and $50 \mathrm{~mm}$ Tris, $\mathrm{pH} 7.5$, and finally with $50 \mathrm{~mm}$ Tris, $\mathrm{pH}$ 7.5. Immunoprecipitated proteins bound to Sepharose were centrifuged at $14,000 \mathrm{rpm}$, supernatant was removed, and the beads were resuspended in SDS sample buffer and boiled for $3 \mathrm{~min}$. Immunocomplexes were fractionated by SDS-PAGE on $12 \%$ polyacrylamide gels and electrotransferred onto Hybond enhanced chemiluminescence (ECL) membranes (Amersham, Uppsala, Sweden) for immunoblotting. Immunoprecipitations of myelin samples were performed using $2.5 \mu \mathrm{l}$ of rabbit polyclonal PMP22 antibodies (D'Urso and Müller, 1997), $5 \mu$ l of a mouse monoclonal P0 antibody (Bollensen et al., 1990), or $2.5 \mu \mathrm{l}$ of rabbit polyclonal myelin basic protein (MBP) antibody (Colman et al., 1982).

Immunoprecipitations of cell lysates were performed using $\sim 200 \mu \mathrm{g}$ of total protein of each sample and following the same protocol described above. In addition to these experiments, we also used an $\mathrm{IgG}_{1}$ mouse monoclonal anti-Flag M2 antibody (IBI, Eastman Kodak, Rochester, NY), and in this case, immunocomplexes were precipitated using protein G PLUS agarose $(25 \mu \mathrm{l} / 100 \mathrm{ml}$ sample; Santa Cruz Biotechnology, Santa Cruz, CA).

No immunoprecipitation of PMP22 complexes was obtained when antibodies were preadsorbed with their corresponding immunogenic peptides (1 mg/ml) (D’Urso and Müller, 1997).

To perform Western blotting analyses, after electroblotting, membranes were blocked overnight at $4{ }^{\circ} \mathrm{C}$ with $5 \%$ nonfat milk in Trisbuffered saline-Tween 20 (TBS-T) (50 mM Tris-HCl, pH 7.4, 0.9\% $\mathrm{NaCl}$, and $0.1 \%$ Tween 20 ). Incubation with primary antibodies diluted in TBS-T was performed for $1 \mathrm{hr}$ at room temperature, followed by extensive washing and treatment with horseradish peroxidase-conjugated anti-rabbit (1:2500; Dianova, Hamburg, Germany) or anti-mouse (1:2000; Dako, Hamburg, Germany) secondary antibodies diluted in TBS-T. Antibody binding was detected using the ECL detection assay (Amersham). The primary antibodies used were the same as those used for the immunoprecipitation experiments, with the exception of $\mathrm{P} 0$, which was detected with a rabbit polyclonal P0 antibody (D’Urso et al., 1990). To determine the size of the protein bands, we routinely used a prestained low-range molecular weight standard as reference (Bio-Rad).

Protein analysis by matrix-assisted laser desorption-mass spectroscopy. Peptide mass fingerprinting is a powerful tool for highly sensitive protein identification. The protein band of $\sim 30 \mathrm{kDa}$ that was coprecipitated together with PMP22 was excised from a Coomassie brilliant bluestained polyacrylamide gel and analyzed by matrix-assisted laser desorption-mass spectroscopy (MALDI-MS) as described by Gevaert et al. (1996). In brief, the gel piece containing the $\sim 30 \mathrm{kDa}$ band was cut out, rinsed several times with distilled water, treated with $50 \mathrm{~mm}$ Tris/ $\mathrm{HCl}, \mathrm{pH} 8.7 /$ acetonitrile $(1: 1 \mathrm{v} / \mathrm{v})$, and then incubated in $50 \mathrm{~mm}$ Tris/ $\mathrm{HCl}, \mathrm{pH} 8.7$, containing $0.1 \mu \mathrm{g}$ of trypsin. The buffer in which proteolytic digestion was performed was removed, and the peptide mixture was analyzed by conventional MALDI-MS (Gevaert et al., 1996).

Deglycosylation treatment of isolated myelin. To remove $N$-linked sugar chains, myelin samples were resuspended in immunoprecipitation buffer (see above) and incubated at $37^{\circ} \mathrm{C}$ for $16 \mathrm{hr}$ in the presence of $1 \mathrm{U}$ of $N$-glycosidase F (PNGase F; Boehringer Mannheim, Mannheim, Germany). Controls were incubated under the same conditions, but no enzyme was added. Then, one-half of each sample was subjected to immunoprecipitation following the procedure described previously in this section. Protein samples were then separated by SDS-PAGE on a $12 \%$ acrylamide gel and analyzed by Western blotting.

Plasmid. We generated a chimeric construct inserting a Flag sequence in frame at the C terminus of the PMP22 (C-Flag-PMP22) coding region before the stop codon (TGA) by PCR. The $5^{\prime}$ primer contained an initiation consensus sequence and 30 nucleotides of the PMP22 cDNA starting at the initiation codon (bp 208-237) (5'-AAGCTTGCCACC ATG CTTCTACTCTTGTTGGGGATCCTGTTC- $3^{\prime}$ ), and the $3^{\prime}$ primer included the Flag sequence (in italics) and 12 nucleotides of the $3^{\prime}$-end of the PMP22 coding region (bp 676-687) (5'-GCTAGCTCA CTTGTCATCGTCGTCCTTGTAGTCTTCGCGTTTCCG-3'). PCR reactions were performed as described in detail by D'Urso and Müller (1997). Amplified cDNA was subcloned into the EcoRI site in the expression vector pcDNA3.1/Hygro(-) (Invitrogen, San Diego, CA), and the validity of the construct was confirmed by restriction analysis and DNA sequencing.

Cell culture and transfection. Transfection experiments were performed using HeLa cells, a cell line derived from a human cervical carcinoma. Cells were cultured in DMEM supplemented with $10 \%$ fetal calf serum, $100 \mathrm{U} / \mathrm{ml}$ penicillin, $100 \mathrm{mg} / \mathrm{ml}$ streptomycin, and $2 \mathrm{~mm} \mathrm{~L}$-glutamine (all supplied by Life Technologies, Gaithersburg, MD) at $37^{\circ} \mathrm{C}$ and $10 \%$ $\mathrm{CO}_{2}$. Clonal lines of $\mathrm{P} 0$ expressors were generated (cotransfected with the plasmids pSV2-neo and P0pECE and selected by G418 resistance) as extensively described by D'Urso et al. (1990) and Doyle et al. (1995). To coexpress $\mathrm{P} 0$ and $\mathrm{PMP} 22$, stable $\mathrm{P} 0$ transformants were transfected with 
the plasmid pcDNA3.1-C-Flag-PMP22 using Lipofectamine (Life Technologies). Liposomes $(4 \mu \mathrm{g} / \mathrm{ml})$ and plasmid DNA $(2.5 \mu \mathrm{g} / \mathrm{ml})$ were mixed in serum-free medium (OPTI-MEM I; Life Technologies) and added to the cultures. After $6 \mathrm{hr}$ incubation, cells were maintained in complete DMEM and then analyzed by immunofluorescence or cultured in medium containing $400 \mu \mathrm{g} / \mathrm{ml}$ Geneticin G418 (Life Technologies) and $200 \mu \mathrm{g} / \mathrm{ml}$ Hygromycin (Calbiochem, San Diego, CA) to select stable double transformants. To generate a clonal cell line of C-Flag-PMP22, naive HeLa cells were transfected with the pcDNA3.1-C-Flag-PMP22 plasmid following the same protocol described above and selected in medium containing $200 \mu \mathrm{g} / \mathrm{ml}$ Hygromycin.

Cell lysates. Control and P0-PMP22 expressing HeLa cells were grown to confluency on $100 \mathrm{~mm}$ Petri dishes, cultured in the presence of $5 \mathrm{~mm}$ sodium butyrate overnight, washed three times with ice-cold PBS, scraped off the dish, and pelleted at $1000 \mathrm{rpm}$ for $5 \mathrm{~min}$ at $4^{\circ} \mathrm{C}$. After centrifugation, supernatants were discarded, and pellets were resuspended in an adequate volume of lysis buffer containing $150 \mathrm{~mm} \mathrm{NaCl}$, $1 \%$ Triton X-100, $5 \mathrm{~mm}$ EDTA, $10 \mathrm{~mm}$ Tris, $\mathrm{pH} 7.4,1 \mu \mathrm{g} / \mathrm{ml}$ pepstatin, $1 \mu \mathrm{g} / \mathrm{ml}$ leupeptin, and $1 \mu \mathrm{g} / \mathrm{ml}$ aprotinin. After incubation at $4^{\circ} \mathrm{C}$ with gentle rocking, total protein concentration of the crude cell lysates was determined with a Bio-Rad assay kit, and samples were stored at $-20^{\circ} \mathrm{C}$ until use.

Immunofluorescence and confocal microscopy. Before immunostaining, transfected cells were plated on poly-L-lysine-coated glass coverslips and cultured overnight in complete DMEM containing $5 \mathrm{mM}$ sodium butyrate. Butyrate treatment has been shown to boost transcription of recombinant plasmid in mammalian cells (Gorman et al., 1983) and, in particular, increases by several fold the level of P0 expression in our system (Doyle et al., 1995). For double immunofluorescence, cells were fixed in $4 \%$ paraformaldehyde for $10 \mathrm{~min}$ at room temperature, washed with PBS, pH 7.4, and permeabilized with $0.1 \%$ Triton X-100 in PBS for 5 min. Incubation with first antibodies was performed at room temperature for $1 \mathrm{hr}$, followed by extensive washing and treatment with secondary antibodies also for $1 \mathrm{hr}$ at room temperature. Finally, coverslips were rinsed in PBS and mounted on slides with a mixture of $2.5 \%$ DABCO (Sigma) in glycerol and PBS. To detect only extracellular immunostaining, live cells were incubated with primary antibody before fixation, and no permeabilization was performed. As primary antibodies, we used affinity-purified rabbit P0 (1:25) or PMP22 (1:200) polyclonal antibodies (D'Urso et al., 1990; D'Urso and Müller, 1997) and a mouse monoclonal anti-Flag-M2 (1:150; IBI, Eastman Kodak). Primary antibodies were visualized using affinity-purified Cy3-conjugated goat anti-rabbit $(1: 300$; Dianova) or fluorescein-conjugated goat anti-mouse (1:25; Southern Biotechnology, Birmingham, AL) secondary antibodies.

Indirect immunoflorescence images of labeled samples were acquired by laser-scanning confocal microscopy (MRC 1024; Bio-Rad) and photographed using an image recorder (Focus Graphics).

\section{RESULTS}

\section{PMP22 and P0 form specific complexes at the myelin membrane}

Several lines of evidence have shown a strong correlation between PMP22 dosage and function, which may indicate that the protein is required at the plasma membrane in a precise amount. This prompted us to investigate whether PMP22 interacts with another protein or complex of proteins at the myelin membrane. To address this issue, we immunoprecipitated possible PMP22 complexes from myelin isolated from rat sciatic nerve using polyclonal anti-PMP22 antibodies. We separated these complexes on a $12 \%$ polyacrylamide gel by SDS-PAGE, and we looked at their composition. Silver staining of the gel revealed that, in addition to PMP22, another protein band of $\sim 30 \mathrm{kDa}$ was specifically coprecipitated (Fig. 1). MALDI-MS and Western blotting analyses identified this protein as the peripheral myelin protein zero (Fig. $2 A$ ). In particular, all the peptide sequences obtained from the mass spectrometry analysis after proteolitic digestion matched with the rat myelin protein P0. Furthermore, we obtained identical results using two different PMP22 antibodies that both specifically recognize PMP22 protein in Western blots and immunofluorescence microscopy, as we have demon-

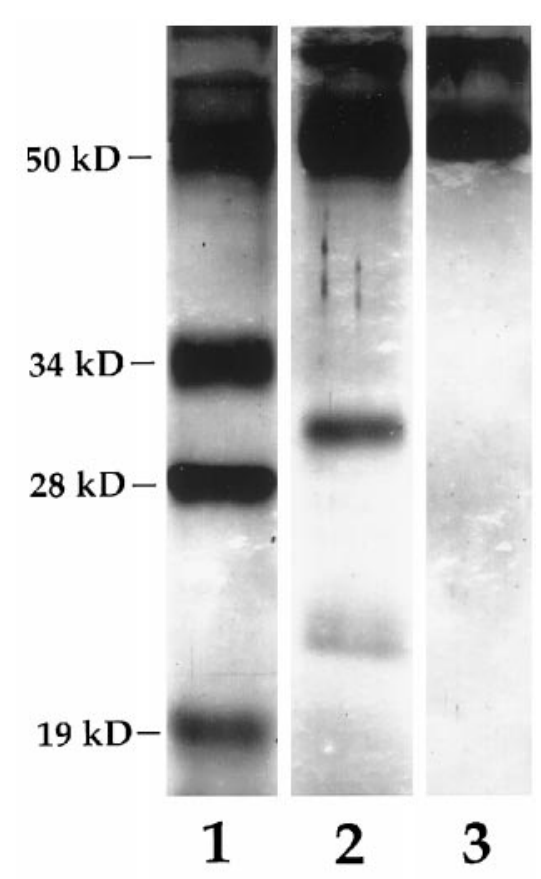

Figure 1. Immunoprecipitation of PMP22 complexes from purified PNS myelin. A total myelin protein preparation was immunoprecipitated using a polyclonal anti-PMP22 antibody. PMP22 complexes were separated by SDS-PAGE, and silver staining of the gel showed that a protein of $~ 30$ kDa coimmunoprecipitated specifically with PMP22 (22 kDa) (lane 2). No proteins were precipitated when the antibody was preadsorbed with the corresponding synthetic oligopeptide (lane 3) or when myelin was omitted from the immunoprecipitation mix (data not shown). Lane 1 represents the molecular weight standards. The $\sim 53 \mathrm{kDa}$ band present in lanes 2 and 3 corresponds to the heavy chain of $\mathrm{IgG}$.

strated previously (D’Urso and Müller, 1997). To verify the specificity of these data, we performed reciprocal experiments. We immunoprecipitated purified myelin using an anti-P0 antibody, and together with P0 we pulled down only PMP22 (Fig. $2 A)$; no other specific protein bands were isolated from the precipitated complexes. Preincubation of PMP22 antibody with the immunogenic peptide abolished PMP22 immunoprecipitation, as well as coimmunoprecipitation of P0 (Fig. 1, lane 3). In vivo and in vitro studies (Haney et al., 1996; D'Urso et al., 1997) have shown that $\mathrm{P} 0$ and PMP22 proteins strictly colocalize in compact myelin. Because MBP is the another protein known to be present at this site, where it is associated with the cytoplasmic aspects of the myelin membrane, we also tested for complexes formed between PMP22 and MBP. Using anti-MBP antibodies, only the protein bands corresponding to the four MBP isoforms expressed in rat myelin (Colman et al., 1982) were precipitated (Fig. 2B), and no PMP22 signal was detectable. On the other hand, no MBP was coprecipitated with PMP22 antibody (Fig. $2 B)$. Blots of MBP precipitates were negative also when probed with $\mathrm{P} 0$ antibody (data not shown). These experiments indicated that the formation of PMP22-P0 complexes was specific and not caused by unspecific adhesiveness of the two proteins or by the presence of large membrane aggregates of the myelin preparation. All immunoprecipitations were performed under stringent conditions in buffer containing $0.1 \%$ SDS, and coimmunoprecipitates were isolated after being rinsed in the presence of high-salt concentration. 
A
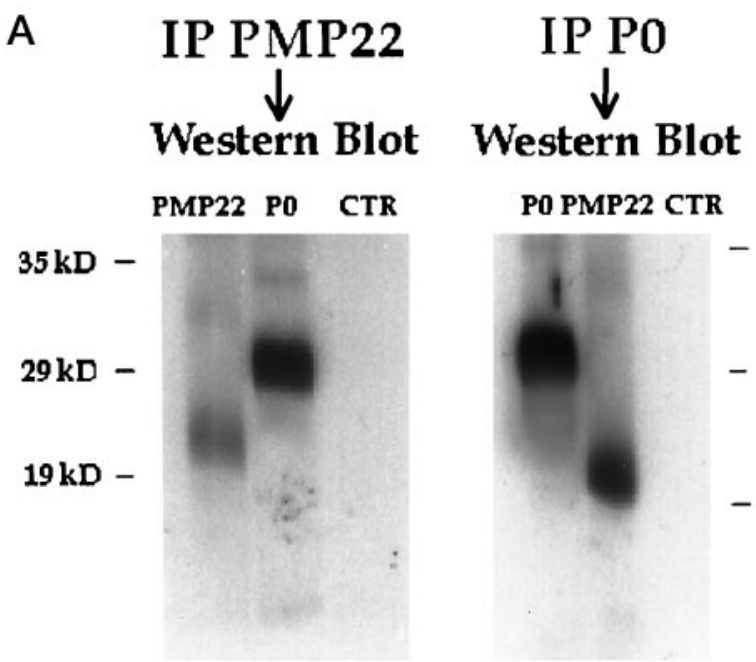

PO PMP22 CTR

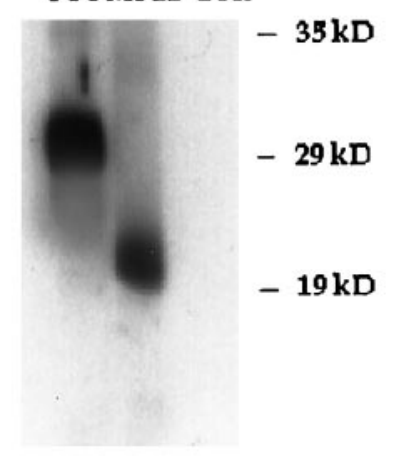

B

IP MBP IP PMP22
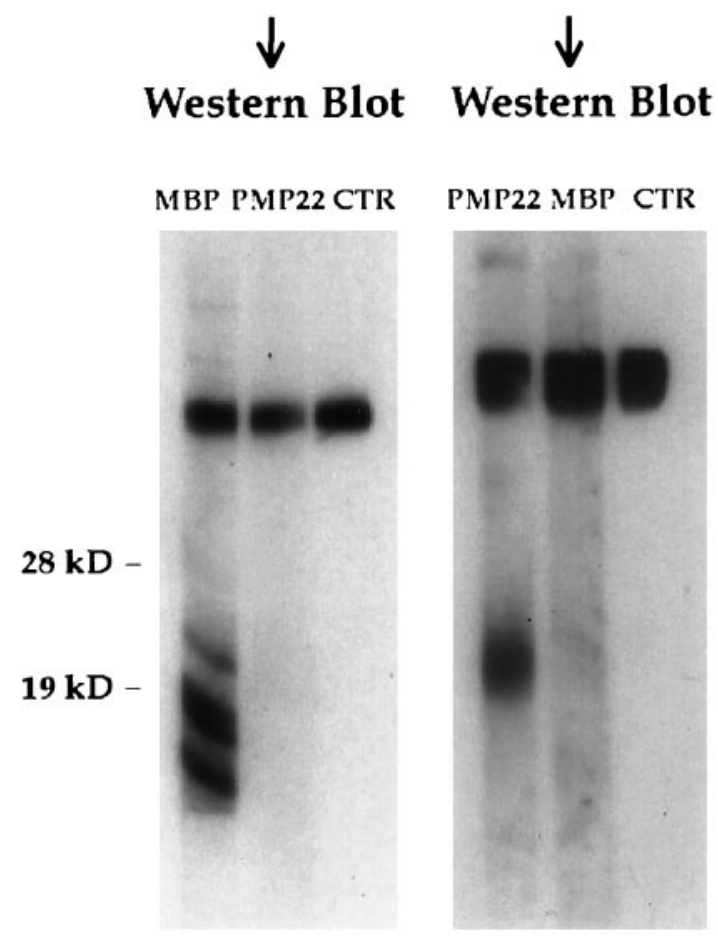

PMP22 MBP CTR

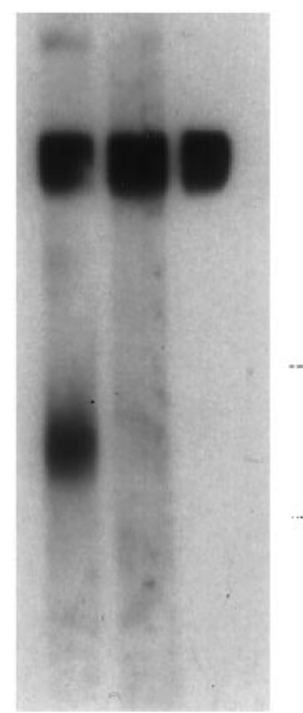

$-28 k D$

$19 \mathrm{kD}$

Figure 2. Detection of PMP22-P0 complexes in isolated myelin. $A$, Purified myelin was immunoprecipitated $(I P)$ using either anti-PMP22 or anti-P0 antibodies. Western blots demonstrated the presence of $\mathrm{P} 0$ in the PMP22 precipitates; similarly, PMP22 was detected in P0 immunoprecipitates. $B$, Western blots of immunoprecipitates isolated using antiMBP antibodies recognized only the four MBP isoforms and no PMP22. No MBPs were present in PMP22 immunoprecipitation. The $\sim 53 \mathrm{kDa}$ band present in all lanes corresponds to the heavy chain of IgG. In $A$ and $B, C T R$ indicates blots probed only with secondary antibody.

\section{$N$-glycosylation is not critical for PMP22-P0 association}

PMP22 and P0 are both glycosylated proteins that carry an $N$-linked sugar chain in their extracellular domains at Asn 41

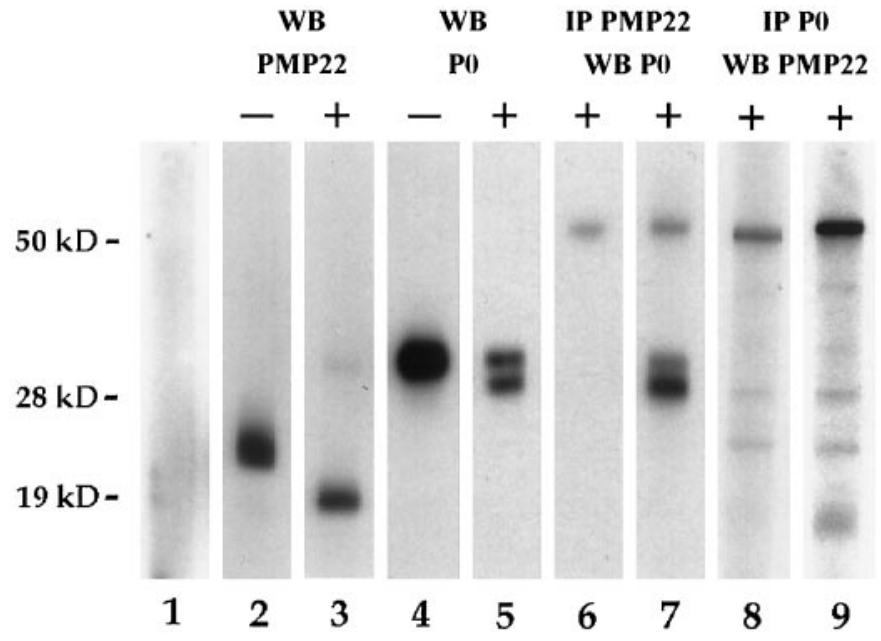

Figure 3. Deglycosylation does not affect the formation of P0-PMP22 complexes. Purified myelin was treated with $N$-glycosidase F. Western blots $(W B)$ of untreated $(-)$ and treated $(+)$ myelin were probed with PMP22 (lanes 2,3) or P0 (lanes 4, 5) polyclonal antibodies to assess the result of the enzymatic digestion. The blot in lane 1 was incubated only in the presence of the secondary antibody. In lane 3, a PMP22 band of $\sim 18.5$ $\mathrm{kDa}$ is visible, indicating completed deglycosylation. Under the same experimental conditions, $\mathrm{P} 0$ was partially deglycosylated, as indicated by the presence of two bands of $\sim 30$ and $\sim 28.5 \mathrm{kDa}$ (lane 5). In lanes 6 and 7 , Western blots of deglycosylated myelin immunoprecipitated $(I P)$ with PMP22 antibody and probed with P0 (lane 7) or only secondary (lane 6) antibodies. Lanes 8, 9, Western blots of deglycosylated myelin immunoprecipitated with P0 antibody and probed with PMP22 (lane 9) or only secondary (lane 8) antibodies.

(Manfioletti et al., 1990; Snipes et al., 1992b) and Asp 93 (Lemke and Axel, 1985; Bollensen and Schachner, 1987), respectively. Carbohydrate residues have been implicated in mediating protein-protein interactions. In particular, it has been reported that glycosylation of $\mathrm{P} 0$ seems to be important for this protein to function as a homophilic adhesion molecule (Filbin and Tennekoon, 1991). To determine whether the sugar moieties are involved in the formation of PMP22-P0 complexes, we immunoprecipitated these complexes from myelin pretreated with PNGase F (Fig. 3). Western blots of deglycosylated myelin proteins showed that, under the conditions optimized to perform the immunoprecipitation experiments, oligosaccharide chains were completely removed from the PMP22 molecule (Fig. 3, lanes 2, 3), resulting in an $\sim 18.5 \mathrm{kDa}$ protein band, whereas only partial digestion was obtained for P0 (Fig. 3, lanes 4, 5). After enzymatic digestion, we detected two P0 bands in immunoblots of PMP22immunoprecipitated myelin proteins, corresponding to the glycosylated form $\left(M_{\mathrm{r}}\right.$ of $\left.\sim 30,000\right)$ and to the totally deglycosylated P0 molecule $\left(M_{\mathrm{r}}\right.$ of $\left.\sim 28,500\right)$ (Fig. 3, lanes 6,7$)$. In reciprocal experiments performing Western blotting of P0 immunoprecipitates, PMP22 antibody recognized the expected band $\left(M_{\mathrm{r}}\right.$ of $\sim 18,500$ ) corresponding to the deglycosylated protein (Fig. 3, lanes 8,9 ). These results indicate that the HNK1 epitope does not play a crucial role in the heterophilic interactions between $\mathrm{P} 0$ and PMP22.

\section{PMP22 and P0 proteins colocalize in the plasma membrane of transfected HeLa cells}

During myelination, P0 and PMP22 are readily targeted to the plasma membrane and colocalize in compact myelin. Interestingly, the segregation of these proteins to the same membrane aspects takes place also when they are expressed in a heterologous 
system. Stable P0 transformants of HeLa cells, established in previous experiments (D'Urso et al., 1990; Doyle et al., 1995), were transfected with a plasmid [pcDNA3.1/Hygro $(-)]$ containing the rat PMP22 cDNA engineered with an octapeptide epitope tag (Flag) inserted in frame at the $\mathrm{C}$ terminus of the coding region. The Flag $\mathrm{C}$ terminus epitope does not interfere with the cellular sorting and membrane targeting of the PMP22 protein, as we have demonstrated previously (D'Urso and Müller, 1997; D'Urso et al., 1998). The P0 and PMP22 antibodies available for Western blotting and immunofluorescence analyses were both polyclonals; therefore, the expression of tagged PMP22 (C-FlagPMP22) and the use of monoclonal anti-Flag antibody allowed us to detect simultaneously both proteins by double immunostaining in the same samples. Confocal microscopy revealed that, in double transfectants, PMP22 exhibited the expected membrane distribution, as described previously in HeLa cells that stably expressed PMP22 alone (D'Urso et al., 1998). Interestingly, in P0-PMP22 coexpressing cells, P0 and Flag immunoreactivities were concentrated at the cell-cell boundaries of expressors in which the two antigens exactly colocalized (Fig. $4 A$ ); this pattern was consistently observed in all the experiments performed.

It has been demonstrated extensively that P0 behaves as a homophilic adhesion molecule through interactions of its extracellular domain (D’Urso et al., 1990; Filbin et al., 1990; Schneider-Schaulies et al., 1990). In particular, transfection experiments have shown that when $\mathrm{P} 0$ expressors are in contact with each other, P0 immunofluorescence highly concentrates along the apposed plasma membrane surfaces. Such restricted accumulation is never observed when P0 expressors make contacts with control nonexpressing cells in monolayers (D’Urso et al., 1990), in suspension cultures (Filbin et al., 1990; Doyle et al., 1995), or with cells expressing other myelin proteins, such as MBP or myelinassociated glycoprotein (D. D'Urso, unpublished observations). We cultured a single cell suspension composed of a mix of cells expressing P0 and cells expressing Flag-tagged-PMP22, respectively. By double immunostaining and confocal analyses of the cocultures, we observed that $\mathrm{P} 0$ was recruited not only at borders between P0 transformants but also at the cell-cell interfaces of P0 and PMP22 expressors (Fig. 4B, arrows).

\section{Heterologously expressed PO and PMP22 coimmunoprecipitate}

To investigate whether the formation of P0-PMP22 complexes is a specific feature of the myelin membrane or whether it can take place also in a neutral environment, we challenged these interactions in HeLa cells, a cell line of epithelial origin that has been used previously for functional studies of myelin proteins (D'Urso et al., 1990, 1998; Doyle et al., 1995; Staugaitis et al., 1990; Pedraza et al., 1997). We generated a clonal cell line that coexpressed both P0 and C-Flag-PMP22. Double transformants were selected in medium supplemented with antibiotics. Confocal laser microscopy of double immunostained cultures showed that P0 (Fig. 4C) and Flag (Fig. 4D) immunoreactivities overlapped in coexpressing cells (Fig. $4 E$ ). Furthermore, in these cultures, we detected PMP22 at the cell surfaces (Fig. $4 F$ ) when immunostaining was performed on nonpermeabilized cells using an antiPMP22 antibody raised against the second extracellular domain of the protein (D’Urso and Müller, 1997).

Western blotting performed with anti-P0 (Fig. 5, lanes 1,2) and anti-Flag (Fig. 5, lanes 3, 4) antibodies demonstrated that both proteins were specifically detected in cell lysates prepared from the clonal line. We used this in vitro model to test for P0-PMP22 binding by coimmunoprecipitation.

Immunoblotting of complexes precipitated by PMP22 antibody revealed the presence of $\mathrm{P} 0$ (Fig. 5, lane 6), and, conversely, PMP22 was coimmunoprecipitated by P0 antibody, as demonstrated by Western blotting performed using anti-Flag (Fig. 5, lane 7) or anti-PMP22 (data not shown) antibodies. No signals were detected in immunoblots performed on cell lysates prepared from control cultures (Fig. 5, lane 5). These results further confirm that P0 and PMP22 participate in the same complexes, and indicate that, most likely, these interactions take place independently from the environmental milieu. In addition, these in vitro experiments demonstrate that clonal cell lines represent a reliable model to further characterize the nature of such interactions.

\section{DISCUSSION}

For many years, most of the information available about myelin structure and composition have been provided by biochemical and electron microscopy studies. Later, with the rapid development of the molecular biology techniques, genetic analyses and identification of the myelin genes involved in demyelinating diseases have been possible. Still, a big mystery is how the assembly of myelin membrane takes place and how this intriguing and special structure is held together. In this study, we provide the first experimental evidence that P0 and PMP22 form complexes in the peripheral myelin membrane and in an in vitro eucaryotic system. These findings are of particular relevance for a better understanding of myelin assembly in normal and pathological conditions. Alterations occurring in the P0 or in the PMP22 gene are found in patients affected by demyelinating hereditary peripheral neuropathies, such as CMT1B or CMT1A, respectively, DSS, HNPP, and CH (for review, see De Jonghe et al., 1997). However, all affected patients are heterozygotes for the mutated gene and thus express reduced levels of normal protein. Interestingly, a common feature of the disease phenotypes seems to be that myelin is initially formed, and then loss of compaction and demyelination progressively proceeds, indicating that the lower amount of functional protein is not sufficient to sustain a compact myelin sheath. This is supported by the observation that heterozygous transgenic animals, carrying only one copy of the P0 or the PMP22 gene, show a relatively late onset of myelin deficiency (Martini et al., 1995; Adlkofer et al., 1997; for review, see Martini, 1997).

Several lines of evidence have demonstrated that the extracellular domain of P0 has homophilic adhesion capacity (D'Urso et al., 1990; Filbin et al., 1990; Schneider-Schaulies et al., 1990), and it has been suggested that its charged basic cytoplasmic tail could indirectly influence clustering of P0 molecules by interactions with the cytoskeleton (Wong and Filbin, 1996) and lipid head groups (Ding and Brunden, 1994). This, together with the abundance and the restricted distribution of the P0 protein to compact myelin, has lead to the current understanding that the myelin lamellae are held together at the intraperiod line through interactions of the P0 extracellular domains and at the major dense line via its cytoplasmic aspects. This very plausible idea appears to be somehow restrictive because PMP22, a gene that is expressed in different tissues, was found to be transcribed mainly by myelinating Schwann cells in which the protein localizes primarily in compact myelin (Snipes et al., 1992a; D’Urso et al., 1997). Furthermore, the direct association of modifications within this gene with peripheral demyelinating diseases has raised the hypothesis that PMP22 participates in maintaining a functional and 

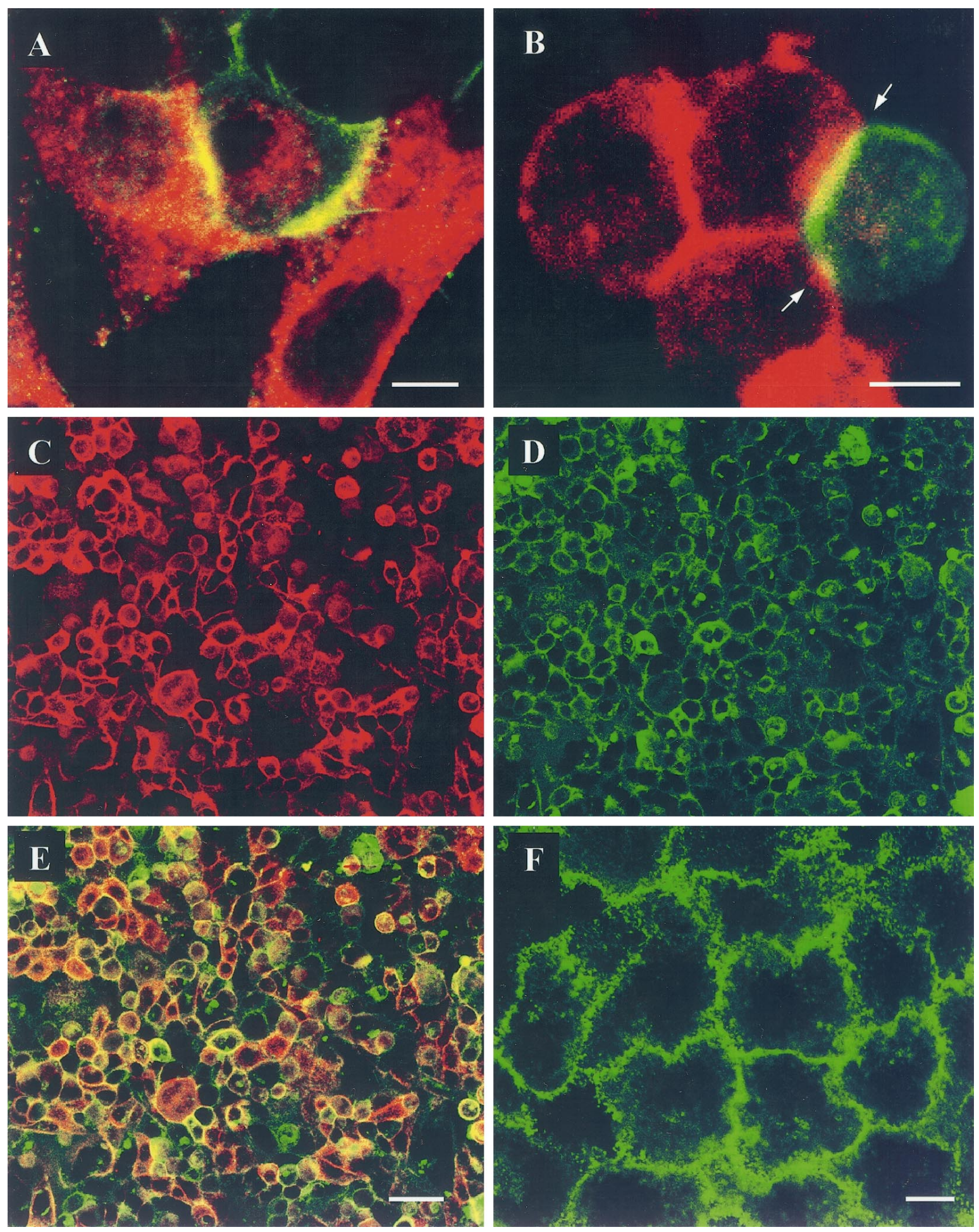

Figure 4. P0 and PMP22 colocalize at the plasma membrane of transfected cells. All panels represent confocal optical sections of immunostained transfected HeLa cell cultures. $A$, HeLa cells that stably express P0 were transiently transfected with tagged Flag-PMP22 and double immunostained using anti-P0 (red) and anti-Flag ( green) antibodies. Both proteins colocalize at the intercellular borders of expressors (yellow). B, Single cell suspensions of P0 expressors and Flag-PMP22 expressors were mixed and cultured in suspension. Aggregates were double immunostained with anti-P0 (red) and anti-Flag (green) antibodies. The yellow signal indicates the presence of both antigens at the cell-cell contact sites (arrows). C-E, Clonal line of HeLa cells that stably express both $\mathrm{P} 0($ red,$C)$ and Flag-PMP22 (green, $D$ ). Colocalization of the two proteins ( yellow) is shown in the merged $C$ and $D$ images $(E) . F$, Nonpermeabilized Flag-PMP22 stable expressors immunostained with an anti-PMP22 antibody directed against an extracellular domain of the protein. PMP22 is detected at the plasma membrane. Scale bars: $A, B, F, 10 \mu \mathrm{m} ; E, 50 \mu \mathrm{m}$. 


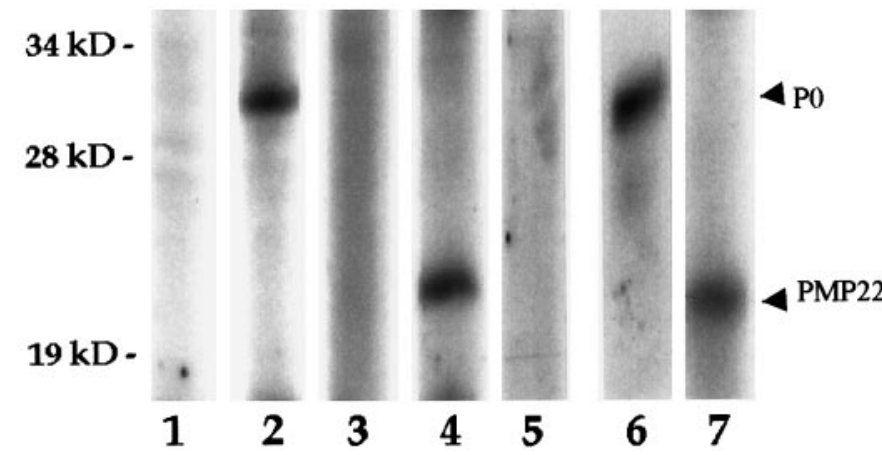

Figure 5. P0 and PMP22 coimmunoprecipitate from cotransfected cells. Cell lysates were prepared from a clonal HeLa cell line coexpressing P0 and Flag-PMP22. The expression of both proteins was analyzed by Western blots probed with P0 (lane 2) and Flag (lane 4) antibody or the respective secondary antibodies only (lanes 1,3 ). No signal was detected in blots of lysates isolated from nontransfected cells and probed with both P0 and Flag antibodies (lane 5). Lane 6, Flag immunoprecipitates of cell lysates that were immunoblotted with anti P0 antibody. Lane 7, P0 immunoprecipitates of cell lysates and Western blots with anti-Flag antibody. Note that P0 and PMP22 coimmunoprecipitate.

stable compact myelin structure. By showing that P0 and PMP22 associate at the plasma membrane, we provide a missing link that can explain why mutations in either of these genes lead to a similar disease phenotype. We hypothesize that the formation of the protein complexes could be affected by either the incorporation of (misfolded) mutated proteins or the decreased availability of one of the protein partners attributable to impaired membrane targeting. Interestingly, we have demonstrated recently that two PMP22 mutants (L16P and G150D), which cause a disease phenotype in humans (CMT1A and DSS) and mice (Trembler $\mathrm{J}$ and Trembler), do not reach the cell surface but accumulate in the endoplasmic reticulum-Golgi compartments (D'Urso et al., 1998). Furthermore, it seems that two P0 point mutations, N93S and S34C, which have been found in CMT1B and DSS, respectively, do not affect the transport of the protein to the plasma membrane but suppress its adhesive properties (Shapiro et al., 1996) (Li and Filbin, 1997, abstract presented orally at the International Society for Neurochemistry satellite). A model proposed by elegant crystallography studies suggests that in myelin the P0 extracellular domains form a network of tetramers, assembled by four molecules arranged around a central hole. Each tetramer is probably connected to four others, which protrude from the opposite membranes. The size of this molecular net is compatible with the spacing determined for the intraperiod line in peripheral myelin (Shapiro et al., 1996). One might speculate that PMP22, a molecule that is less abundant and relatively small, could be accommodated within the $\mathrm{P} 0$ network; a precise arrangement of $\mathrm{P} 0-\mathrm{P} 0$ and $\mathrm{P} 0-\mathrm{PMP} 22$ complexes is then required to maintain a stable compact myelin sheath. Topology studies have already mapped the orientation of PMP22 within the lipid bilayer (D’Urso and Müller, 1997); analyses of its crystal structure would shed light on the nature of its interactions.

Both $\mathrm{P} 0$ and PMP22 proteins carry a single L2/HNK1 epitope, which is found in many neural recognition molecules and is known to participate in adhesive interactions. Our deglycosylation and coimmunoprecipitation data show that the sugar chains are not directly involved in the formation of P0-PMP22 complexes. Although glycosylation has been proposed to be functionally important (Filbin and Tennekoon, 1991), it does not seem to be essential for either the homophilic P0-P0 (Griffith et al., 1992) or heterophilic P0-PMP22 (this study) interactions; thus, the precise function of the sugar moiety is still unclear and awaits further investigation.

Furthermore, here, we have shown that P0 and PMP22 interact also when coexpressed in cells of non-neural origin. Both proteins are targeted to the plasma membrane in which they accumulate at the same sites, as indicated by the results obtained by combining immunofluorescence and confocal microscopy. The immunoprecipitation experiments provide evidence for the association of these proteins at those sites. This confirms the ability of P0 and PMP22 to interact, and it also indicates that formation of these complexes is a bona fide phenomenon for which the myelin membrane environment is not an essential requirement.

Based on in vitro studies, it has been proposed previously that clustering of P0 molecules at the cell-cell boundaries strengthen its adhesive homophilic properties (D’Urso et al., 1990; Wong and Filbin, 1996). Interestingly, here, we show that in transfected cells the presence of PMP22 on the adjacent cell membrane is able to trigger the recruitment and/or to maintain the accumulation of P0 at the intercellular borders of PMP22 and P0 expressors. This might suggest that a similar process could take place during myelin compaction. Thus, clonal cell lines of single expressors should provide a suitable cellular model to identify binding domains in the PMP22 and P0 proteins, respectively. In addition, heterologous coexpression of mutated proteins could help to test for the effects of single point mutations on the formation and stability of the molecular network in the plasma membrane.

In summary, our data provide the first direct evidence for the formation of P0-PMP22 complexes at the plasma membrane. These protein interactions probably participate in holding adjacent Schwann cell membranes together and in stabilizing myelin compaction. Our results could explain why genetic alterations in one of the two partner molecules lead to very similar disease phenotypes. Normally, a critical number of functional P0 and PMP22 molecules is necessary to maintain membrane adhesion and myelin compaction. Mutations could affect the amount of functional PMP22 or P0 in the myelin membrane through either impaired membrane targeting of the mutated protein or the disability of the altered protein to establish correct interactions with the partner molecule because of changes in their conformation. We believe that the outcome of the present study provides new insight into the molecular basis of myelin assembly and peripheral dysmyelinating diseases.

\section{REFERENCES}

Adlkofer K, Frei R, Neuberg DH-H, Zielasek J, Toyka KV, Suter U (1997) Heterozygous peripheral myelin protein 22-deficient mice are affected by a progressive demyelinating tomaculous neuropathy. J Neurosci 17:4662-4671.

Bollensen E, Schachner M (1987) The peripheral myelin glycoprotein P0 expresses the L2/Hnk-1 and L3 carbohydrate structures shared by neural adhesion molecules. Neurosci Lett 82:77-82.

Bollensen E, Scheidt P, Schachner M (1990) Production and characterization of monoclonal antibodies to the major peripheral myelin glycoprotein P0. J Neurochem 54:1110-1114.

Colman DR, Kreibich G, Frey AB, Sabatini DD (1982) Synthesis and incorporation of myelin polypeptides into CNS myelin. J Cell Biol 95:1503-1507.

De Jonghe P, Timmerman V, Nelis E, Martin J-J, van Broeckhoven C (1997) Charcot-Marie-Tooth disease and related peripheral neuropathies. J Peripher Nerv Syst 2:370-387.

Ding Y, Brunden KR (1994) The cytoplasmic domain of the myelin glycoprotein P0 interacts with negatively charged phospholipid bilayers. J Biol Chem 269:10764-10770. 
Doyle JP, Stempak JG, Cowin P, Colman DR, D’Urso D (1995) Protein zero, a nervous system adhesion molecule, triggers epithelial reversion in host carcinoma cells. J Cell Biol 131:465-482.

D’Urso D, Müller HW (1997) Ins and outs of peripheral myelin protein22: mapping transmembrane topology and intracellular sorting. J Neurosci Res 49:551-562.

D'Urso D, Brophy PJ, Staugaitis SM, Gillespie CS, Frey AB, Stempak JG, Colman DR (1990) Protein zero of peripheral nerve myelin: biosynthesis, membrane insertion, and evidence for homotypic interaction. Neuron 4:449-460.

D’Urso D, Schmalenbach C, Zoidl G, Prior R, Müller HW (1997) Studies on the effects of altered PMP22 expression during myelination in vitro. J Neurosci Res 48:31-42.

D'Urso D, Prior R, Greiner-Petter R, Gabreels-Festen AA, Müller HW (1998) Overloaded endoplasmic reticulum-Golgi compartments, a possible pathomechanism of peripheral neuropathies caused by mutations of the peripheral myelin protein PMP22. J Neurosci 18:731-740.

Filbin MT, Tennekoon GI (1991) The role of complex carbohydrates in adhesion of the myelin protein P0. Neuron 7:845-855.

Filbin MT, Walsh B, Trapp B, Pizzey J, Tennekoon G (1990) Role of myelin $\mathrm{P} 0$ protein as a homophilic adhesion molecule. Nature 344:871-872.

Gevaert K, Verschelde J-L, Puype M, Van Damme J, Goethals M, De Boeck S, Vandekerckhove J (1996) Structural analysis and identification of gel-purified proteins, available in the femtomole range, using a novel computer program for peptide sequence assignment, by matrixassisted laser desorption ionization-reflectron time-of-flight-mass spectrometry. Electrophoresis 17:918-924.

Giese KP, Martini R, Lemke G, Soriano P, Schachner M (1992) Mouse $\mathrm{P} 0$ gene disruption leads to hypomyelination, abnormal expression of recognition molecules and degeneration of myelin and axons. Cell 71:565-576.

Gorman C, Howard B, Reeves R (1983) Expression of recombinant plasmids in mammalian cells is enhanced by sodium butyrate. Nucleic Acids Res 11:7631-7648.

Griffith LS, Schmitz B, Schachner M (1992) L2/HNK1 carbohydrate and protein-protein interactions mediate the homophilic binding of the neural adhesion molecule P0. J Neurosci Res 33:639-648.

Haney C, Snipes GJ, Shooter EM, Suter U, Garcia C, Griffin JW, Trapp BD (1996) Ultrastructural distribution of PMP22 in Charcot-MarieTooth disease type 1A. J Neuropathol Exp Neurol 55:290-299.

Ionasescu VV, Searby CC, Ionasescu R, Chatkupt S, Patel N, Koenigisberger R (1997) Dejerine-Sottas neuropathy in mother and son with same point mutation of PMP22 gene. Muscle Nerve 20:97-99.

Kuhn G, Lie A, Wilms S, Müller HW (1993) Coexpression of PMP22 gene with $\mathrm{MBP}$ and $\mathrm{P} 0$ during de novo myelination and nerve repair. Glia 8:256-264.

Lemke G, Axel R (1985) Isolation and sequence of a cDNA encoding the major structural protein of peripheral myelin. Cell 40:501-508.

Manfioletti G, Ruaro ME, Del Sal G, Philipson L, Schneider C (1990) A growth arrest specific gene codes for a membrane protein. Mol Cell Biol 10:2924-2930.

Martini R (1997) Animal models for inherited peripheral neuropathies. J Anat 191:321-336.

Martini R, Zielasek J, Toyka KV, Schachner M (1995) Protein zero
(P0)-deficient mice show myelin degeneration in peripheral nerves characteristic of inherited human neuropathies. Nat Genet 11:281-286.

Patel PI, Lupski JR (1994) Charcot-Marie-Tooth disease: a new paradigm for the mechanism of inherited disease. Trends Genet 10:128-133.

Pedraza L, Fidler L, Staugaitis SM, Colman DR (1997) The active transport of myelin basic protein into the nucleus suggests a regulatory role in myelination. Neuron 18:579-589.

Schneider-Schaulies J, von Brunn A, Schachner M (1990) Recombinant peripheral myelin protein P0 confers both adhesion and neurite outgrowth-promoting properties. J Neurosci Res 27:286-297.

Shapiro L, Doyle JP, Hensley P, Colman DR, Hendrickson WA (1996) Crystal structure of the extracellular domain from P0, the major structural protein of peripheral nerve myelin. Neuron 17:435-449.

Snipes GJ, Suter U, Welcher AA, Shooter EM (1992a) Characterization of a novel peripheral nervous system myelin protein (PMP22/SR13). J Cell Biol 117:225-238.

Snipes GJ, Suter U, Shooter EM (1992b) Human peripheral myelin protein 22 carries the L2/HNK1 carbohydrate adhesion epitope. J Neurochem 61:1961-1964.

Spreyer P, Kuhn G, Hanemann CO, Gillen C, Schaal H, Kuhn R, Lemke G, Müller HW (1991) Axon-regulated expression of a Schwann cell transcript that is homologous to a growth arrest-specific gene. EMBO J 10:3661-3668.

Staugaitis SM, Smith PR, Colman DR (1990) Expression of myelin basic protein isoforms in non-glial cells. J Cell Biol 110:1719-1727.

Suter U, Snipes GJ (1995) Biology and genetics of hereditary motor and sensory neuropathies. Annu Rev Neurosci 18:45-75.

Suter U, Moskow JJ, Welcher AA, Snipes GJ, Kosaras B, Sidman RL, Buchberg AM, Shooter EM (1992a) A leucine-to-proline mutation in the putative first transmembrane domain of the $22 \mathrm{kDa}$ peripheral myelin protein in trembler-J mouse. Proc Natl Acad Sci USA 89:4382-4386.

Suter U, Welcher AA, Ozcelik T, Snipes GJ, Kosaras B, Francke U, Billings-Gagliardi S, Sidman RL, Shooter EM (1992b) Trembler mouse carries a point mutation in a myelin gene. Nature 356:241-244.

Valentijn LJ, Baas F, Wolterman RA, Hoogendijk JE, van den Bosch NHA, Zorn I, Gabreëls-Festen AAWM, de Visser M, Bolhuis PA (1992) Identical point mutations of PMP22 in Trembler J mouse and Charcot-Marie-Tooth disease type 1A. Nat Genet 2:288-291.

Warner LE, Hilz MJ, Appel SH, Killian JM, Kolodny EH, Karpati G, Carpenter S, Watters GV, Wheeler C, Witt D, Bodell A, Nelis E, Van Broeckhoven C, Lupski JR (1996) Clinical phenotypes of different MPZ (P0) mutations may include Charcot-Marie-Tooth type 1B, Dejerine-Sottas, and congenital hypomyelination. Neuron 17:451-460.

Welcher AA, Suter U, De Leon M, Snipes JG, Shooter EM (1991) A myelin protein is encoded by the homologue of a growth arrest-specific gene. Proc Natl Acad Sci USA 88:7195-7199.

Wong M-H, Filbin MT (1994) The cytoplasmic domain of the myelin P0 protein influences the adhesive interactions of its extracellular domain. J Cell Biol 126:1089-1097.

Wong M-H, Filbin MT (1996) Dominant-negative effect on adhesion by myelin P0 protein truncated in its cytoplasmic domain. J Cell Biol 134:1531-1541. 